\title{
Energy Efficiency and Economic Aspects of Mining Wastes Utilization within the Closed Cycle of Underground Gas Generator
}

\author{
PIVNYAK Gennadiy ${ }^{1, a}$, DYCHKOVSKYI Roman ${ }^{1, b}$, \\ FALSHTYNSKYI Volodymyr ${ }^{1, c}$ and CABANA Edgar Cáceres ${ }^{2, d}$
}

\author{
${ }^{1}$ National Mining University, Dnipro, Ukraine \\ ${ }^{2}$ National University of Saint Augustine, Peru \\ arector@nmu.org.ua, bdichre@yahoo.com, csergmant@gmail.com, decaceresca@unsa.edu.pe
}

Keywords: mining wastes, utilization, coal gasification, heating process, economical profitability.

\begin{abstract}
Energy efficiency of coal gasification with possible utilization of mining wastes within ecologically closed gas generator cycle has been considered. Technical and technological performance of such gas generator and mechanism of material and heat balance on the basis of the available analytical methods and practices as well as the developed author software have been proposed. Heat carrier formed in the process of coal gasification has been used for the utilization. Temperature of the utilization process within the industrially expedient limits being supported with the help of either activation or attenuation of the gasification process. After specific treatment, organogenic waste and domestic wastes are utilized by means of thermal decomposition within a gas generator. Economic evaluation of the proposed means confirms the expediency of their implementation in mines with industrial and balanced coal reserves as well as within the areas where this energetic source has already been already mined out. Results of this investigation were partially presented on international scientific and practical conference "Forum of Miners - 2017". They contain the researches, which were conducted within the project GP -489 , financed by Ministry of Education and Science of Ukraine.
\end{abstract}

\section{Introduction}

Apart from its direct function (i.e. extraction of coal or other power raw material or mineral raw material), each mine is the enterprise which produces a number of useful or hazardous by-products. Thus, mining enterprises are the sources of considerable amount of waste which can be used as extra component of human life activities, or the waste should be neutralized. The process has to be in full accordance with ecological compatibility of the utilization process. As for the coal mines engaged in underground mining, their waste includes not only barren rock but also great amount of mineralized water and products connected with industrial human activity [1].

Moreover, activities of any coal mine are followed by significant discharge of polluted air containing not only rock and coal dust but also various gases. Currently, mines rarely apply methods for their purification, capture, segregation and further industrial use or utilization.

Another important component of mining is: a mine is a complicated system with various departments which objective is to obtain end product (i.e. coal) having corresponding qualitative and quantitative indicators. Good deal of workers and other staff operate in a mine producing great volumes of domestic waste containing organogenic components, remains of workwear, lubricants, fuel, rubber-containing products and others.

The available utilization methods are far from being efficient as they require both scientific substantiation and technical and technological improvement. Nowadays, the waste treatment involves its storage within specialized areas with its following burning out.

Multigenesis waste formed in the process of mining is rarely utilized at garbage recycling plants. Hence, no components useful for human needs are extracted to be recycled. Gases generated as a result of temperature destruction are not utilized becoming instead the source of extra air pollution. After thermal treatment, various multigenesis waste changes its characteristics and properties; the process complicates its further processing. 
The authors propose integrated solution for the problem. Possibility to utilize mining waste while applying the technology of coal gasification is considered. Moreover, the process should be performed within ecologically closed cycle of underground gas generator. Burning coal (first of all, non-commercial or abandoned coals) will become heat-energy source for its decomposition. The gas mixtures will be filtered with their further use for activation or attenuation of gasification process. Both liquid and solid residuals are segregated with the help of specific devices and filters. The obtained hazardous phenolic, toluene and other residuals are utilized together with organogenic and domestic waste immediately in the gas generator [1].

\section{Available Practices of Mining Waste Utilization}

Accumulations of significant amounts of barren rock as well as rock containing non-commercial useful components are the major waste of mining industry. The waste is a result of the activities connected with blasting, retimbering of development mine workings, underworking of barren rocks in stoppings, illegal dumps and under other emergency situations connected with gas dynamic and dynamic activities of rock mass, coal preparation and extraction of its nonfuel components at mining and preparation plants. As a result, considerable rock dumps (waste piles) are formed at the surface. The dumps are the sources of dust generation; they are often characterized by the increased radiation and self-burning, contaminating the air with hazardous and poisonous gases. Besides, the dumps are the cause of negative mineralization of water, its leakage into water-bearing levels and penetration into fertile soil layers. Moreover, the dumps occupy significant areas including territories which could be used for agricultural purposes. The abovementioned factors into deterioration of ecological situation in mining regions. Consequently, drastic negative signs connected with the problems of drinking water supply and pollution of fertile soil layers occur, resulting in the worsening of population health.

Nowadays leading mining European countries have almost solved the problem of barren rock utilization at the surface. Certain companies engaged in its treatment extract both basic and associated commercial components. Residual barren rock is used as the material for road bedding, surface levelling, ballast addends for solutions or concrete etc. Sometimes hilly lands are formed or artificial systems for wind and solar power generation are developed. Ways and technical and technological features of associated treatment of the extracted barren rock and its industrial use as well as reorientation of the activity within post mining areas are described in detail by specialized scientific sources [2,3,4 etc.].

Ground water penetrating through water-bearing levels into underground mine workings is a significant problem as well. As it is known, the water drifts throughout mine workings and accumulates within a water collector of a shaft sump. Further, water is pumped out to the surface into special segregators where the water is purified for its following use. The most complicated process is mine water demineralization up to drinking water standards. The process involves both chemical and biological techniques which, unfortunately, are very costly; that is why they are rarely used in mines [2,3,4 etc.].

Movement of air masses along mine workings also results in their composition changes. In addition to natural sources, they pollute mine atmosphere (methane, carbon dioxide); besides, there are technogenic sources of hazardous gas emissions. First, they include nitrogen oxides formed in the process of drilling and blasting. All the air masses get to the surface with the following emission to the atmosphere. Currently, there are several cases when methane of the return air stream is used industrially. The authors of the paper propose to use underground coal gasification as one of the tendencies to utilize gas mixtures from the mines [2,3,5 etc.].

Municipal (domestic) wasteы as well as organogenic residuals of mining and other industrial activities are a burning problem. Actually, there is no unified approach to the utilization of the products. Another serious problem of waste utilization as well as all the technogenic residuals of mining is the imperfection of legislation for environmental protection. A number of legislative acts regulating nature protective relations within "mine-society" system have been adopted. However, fundamental contradictions of the legislative acts form the basis for wrongdoings and various non- 
normative relations while implementing environmentally friendly solutions for the regions. That deepens rather unstable situation of depressive areas where mines either operate or have already completed their activities. It is utilization and possible recycling of the products while processing of multigenesis wasteы the research by the authors of the paper is focused on.

\section{Preparation of Organogenic and Domestic Waste for its Utilization}

The anticipated technique to utilize municipal, domestic, and organogenic waste formed as a result of mining and other industrial activities involves the development of corresponding technological schemes, introduction of structural peculiarities and application of innovative methods to control a process of kinetics of thermochemical reactions and physical velocities of their course within underground gas generator. Much attention is also paid to the techniques of gas generators preparation. In this context not only preparation of underground gas generator is important, but also its surface simulation as the main objective of its operation is the destructive thermal effect on the waste.

If gas generators are prepared in a mine, then waste can be delivered directly into reaction channel through the gas supply well. The construction of separate wells to supply catalytic substances, activators or inhibitors of gasification processes together with waste is also possible. Technical and technological improvement of waste utilization process envisages formation of technogenic cavities near the coal pillars being left along the length of a mined seam and their filling with the mentioned waste.

Preliminary preparation of the mentioned waste is the important component of its efficient processing. It goes without saying that the waste should be separated before gasification according to its qualitative composition and geometry. Following stage involves its crushing and blending to obtain a mixture of the required consistency. If necessary, combustible agents (first of all, coal or masut are meant) are added to the mixture. Preliminary pyrolysis or nitrogen hardening of the products before gasification is admissible.

Extra stresses resulting in more complete decomposition of the waste and in preliminary deactivation of carcinogenic and poisonous substances occur in the products after such treatment. Depending upon gasification process applied, utilization of the waste may be carried out with the help of combined technique: pyrolysis and impulse supply of a forced draft mixture. It results in the formation of purer complex gasification product.

\section{Chemical and Physical Basis for the Carbon Hydrate Waste Decomposition within Closed Cycle of Underground Gas Generator}

Authors of the paper as well as other members of our science team are experienced in waste utilization within closed cycle of underground gas generator. The results are represented in a number of scientific works [6-9]. Further studies made it possible to improve and complete the process of kinetic formation during the procedure as well as to develop physical and chemical substantiation concerning waste processing with the help of WUCG:

1. Depending upon qualitative composition and availability of the required combustible or other agents within waste structure, its utilization may be directed to a complete, thermally destructive disposal; however, its transformation into useful gas components for further application (including that in a closed cycle of gas generator) is more promising alternative.

2. In the process of chemical transformation of a condensed phase, pressure change is not very important for balanced stages of reagent transformation; thus, it is necessary to search for other paths to activate or inhibit gasification process.

3. Phenol compositions, toluene compositions, and other poisonous compositions are added to the abovementioned waste being supplied to georeactor for their further thermal decomposition and utilization; gas residuals of the useful mixture are captured with the help of special filters to be segregated and reused. 
4. Gasification process activation takes place in the course of exothermal reaction in the context of uncontrolled decrease of temperature resulting in physical deceleration of chemical reactions; additional circulation up to secondary thermal decomposition is applied directly in the georeactor within the lower stage of reagent transformation.

5. Temperature increase in case of exothermal reaction results in acceleration of both basic and side reactions; in this context selectivity of gasification process decreases and problems with the reuse of the obtained gas mixtures arise.

6. Ash residuals are washed out either right after the gasification process has been completed or it is deactivated or conserved immediately within the gas generator with the help of specific mixtures (as a rule, the mixtures are clay-based).

7. In the context of minor variability and thermal effect of chemical reactions, temperature changes are not important for a balance of product transformation stage; that makes it possible to utilize mining waste in a rather stable manner.

8. Catalytic action of certain chemical components or compounds helps focusing on a process of multigenesis waste processing while obtaining useful components; besides, it helps increase the content of the required technical or power gases without any changes in the technology of WUCG process itself as well as the modes of supply of forced-draft mixtures into working space of the georeactor reducing considerably the end product cost.

9. If argillaceous or other soft rocks acting as natural safety screens are not available above the underground gas generator and rather fissured rocks are available, then artificial segregation of the gas generator should be applied. The segregation is performed with the help of specific mixtures injection into the rocks. The mixtures fill in the rock fissures densely, becoming stable ceramic substances under the temperature action.

10. The development of new selective systems providing high velocity and selectivity of the utilization itself is a promising solution for the problem of multigenesis waste processing with the help of underground gasification.

Destructive action of high temperatures $\left(900-1200{ }^{\circ} \mathrm{C}\right)$ shows that practically all the abovementioned waste will be utilized completely. All chemical connections will be broken with the formation of radicals. It results from the fact that pyrolytic decomposition of carbohydrates of coal, oil or masut takes place at the temperature of $350-450{ }^{\circ} \mathrm{C}$; breakage of alkyl-chlorine connections needs $250-300{ }^{\circ} \mathrm{C}$ temperature. Chemical transformations of organic structures take place at 150-200 ${ }^{\circ} \mathrm{C}$ temperatures.

Energy of compound breakages depends upon the nature of components which united them into one system as well as upon the features of the structure of radicals forming them. The more stable the formation of free organic radicals is, the easier the process of such connection breakage is. Centered stresses with mutual repulsion in the outcoming group of molecules are observed. Their geometry is important favouring homolysis of the connections even more. The effect is mostly seen in the process of decomposition of nitrogen compounds and nitrogen containing waste. Paper [9] demonstrates results of the obtained temperatures, kinetic parameters of hemolytic decompositions of molecules and kinetic parameters of thermolysis of nitrogen compounds in the process of monocular reactions of different-type homolysis.

If coordinated homolysis of certain relations and formation of new relations take place in parallel, then the total process will be more energetically advantageous than a simple process of homolysis. Homolytical decomposition consumes less energy with the participation of one more molecule in the reaction if a new molecule with the participation of other molecules is formed and if simultaneously with the homolysis of one connection a formation of new compound will be provided with the participation of other molecules which decreases total required energy consumption for their formation [10].

Flash temperature (ignition of the georeactor) is important for the process of the abovementioned waste processing like for any thermal process. In the context of considerable thermal capacity and insignificant thermal conductivity of the system where the thermochemical process takes place, heating-up of the reaction medium is one of the essential components as incomplete utilization of the 
mentioned multigenesis waste takes place at the stage when the system starts operating at the level of working temperatures.

If the system is characterized by exothermal reaction, then the dependence of the reaction velocity should be expressed in accordance with Arrhenius law in the form of $[9,10]$ :

$$
\frac{d T}{d t}=\frac{v_{0} q}{\rho c} e^{-\frac{E}{R T}}-\frac{\propto\left(T-T_{0}\right)}{\rho c} \frac{s}{V}
$$

where $\rho$ is the density of reaction mixture; $\mathrm{c}$ is specific thermal capacity; $e^{-\frac{E}{R T}}$ is physical and chemical velocity of the reaction; $\mathrm{q}$ is thermal effect; T0 is the environmental temperature; $\alpha$ is the coefficient of thermal transfer from the reaction channel medium to the environment; $\mathrm{S}$ is the surface area of the reaction channel of the georeactor; $\mathrm{V}$ is working capacity of the reaction channel section.

Calculation of flash temperature (the georeactor system ignition) is possible when coefficient of thermal transfer $\alpha$ is determined. According to the assumptions by D.A. Frank-Kamenetskii, when the condition of coal ignition $(\beta)$ for a cylindric-shape vessel with the infinite length, then a value of the index will be

$$
\beta=\frac{v_{0} q}{\lambda} \rho^{2} \frac{E}{R T_{0}^{2}} e^{-\frac{E}{R T_{0}}}=2.00
$$

Use of such ratios as well as principles from [10,11] will help calculate flash temperature for substances having various compositions. When different industrial, municipal, and organic substances experience their decomposition in a gas phase, then the process in the system of underground gas generator takes place according to the first-order reactions. According to the previous form, $\beta$ will be within $1.0-1.3$. Hence, flash temperature T0 will not be higher than $650-6750 \mathrm{~K}$. The required supplied heat (the emitted heat resulting from burning of coal and combustible components of the prepared waste mixture) will not exceed $1800 \mathrm{~kJ}$ in the context of heat content change up to $2400 \mathrm{~kJ}$ in the process of waste utilization with the help of gasification technique in underground gas generators at the expense of applying forced-draft mixtures of different compositions, various techniques of their preparation, and their supply to the georeactor. Thus, bringing the gas generator to its working temperature $\left(\mathrm{T}=900-1100^{\circ} \mathrm{C}\right)$ as well as the effect of the temperature on the mentioned waste makes it possible to utilize them efficiently or process them to reuse their useful components.

\section{Technical and Technological Basis and Material Balance}

Consider a scheme with extra well to be used for the mentioned waste delivery up to their processing point (Fig.1) for technical and technological substantiation of multigenesis industrial waste utilization by means of coal gasification within environmentally sound cycle of the georeactor. This particular well is proposed to be used for the delivery of other chemical reagents which, depending upon the gasification process and the necessity of its control, will be either activators or inhibitors. Processing of multigenesis waste focused on the production of other useful components is another important task.

The authors used special-purpose plant to carry out the analysis concerning the possibility to utilize waste aimed at the obtaining of various power gases. Paper [1] gives rather complete explanation of technical characteristics and operational principles of the plant. Waste was prepared with the focus on averaged chemical composition of municipal waste from mining enterprises. Also it can be used the wastes of other human domestic and industrial activityю Flash was performed by the formation of coke ignition as well as its placement within the reaction channel and supply of oxygen-saturated air mixture. Operation gasification modes were analyzed while applying following types of forced-draft mixtures: an air mixture; a mixture saturated with oxygen up to $25 \%$ in post-reverse mode; a mixture saturated with oxygen up to $30 \%$ and water vapour up to $20 \%$; and a mixture saturated with oxygen up to $27 \%$ and water vapour up to $15 \%$.

Separately, there were analyzed changes in temperatures and gas compositions of outcoming gas generator flow (material and thermal balance of WUCG) while applying impulse supply of air forced- 
draft mixtures which oxygen saturation was $25 \%$ and water vapour saturation was $12 \%$. Selection of the results concerning composition changes in the obtained gas components was performed according to the current scheme with the help of such devices as BX - 170 and Casboard - 3200L; the data were displayed with the help of proper software package. It is necessary to mentioned that software was adopted by our research group for the bordering parameters for each types of used coal and for different blowing mixtures.

Special attention was paid for the preparing wastes, which were utilized. They had been primarily destructed by special worm crushers, and together with inhibitors or activators of gasification process were directed to gas generator. So it was necessary to conduct different patterns of prepared incoming products, which were utilized.

Nor less than 50 samples were taken according to each experiment, and general data concerning possibilities to get generator mixtures within the composition of technical and power gases were obtained; moreover, general principles to generate the gases for their further commercial use were formulated. Table 1 represents the results of averaged composition of generator gases in the process of the experiments.

Table 1 Composition of generator gases while carrying out the experiment

\begin{tabular}{|c|c|c|c|c|c|c|c|c|}
\hline \multirow{2}{*}{ Type of forced draft } & \multicolumn{7}{|c|}{$\begin{array}{c}\text { Components of generator gas, average values according to } \\
\text { the experiment }\end{array}$} & \multirow{2}{*}{$\begin{array}{c}\text { Lower } \\
\text { boundary } \\
\text { of gas- } \\
\text { burning } \\
\text { heat, mJ }\end{array}$} \\
\hline & $\mathrm{CH}_{4}$ & $\mathrm{CO}$ & $\mathrm{H}_{2}$ & $\begin{array}{c}\mathrm{CH}_{4}+ \\
\mathrm{CO}+\mathrm{H}_{2}\end{array}$ & $\mathrm{CO}_{2}$ & $\mathrm{~N}_{2}$ & $\mathrm{O}_{2}$ & \\
\hline Flash & 0.98 & 1.65 & 1.20 & 3.83 & 6.77 & 77.20 & 12.2 & 0.68 \\
\hline Air force draft & 3.36 & 5.65 & 4.82 & 13.83 & 8.48 & 75.50 & 2.19 & 2.43 \\
\hline $\begin{array}{c}\text { Forced draft saturated with } \\
\mathrm{O} 2-25 \% \text {, post-reverse mode }\end{array}$ & 4.09 & 8.96 & 8.04 & 21.09 & 1.06 & 74.56 & 3.29 & 3.91 \\
\hline $\begin{array}{l}\text { Forced draft saturated with } \\
\mathrm{O} 2-30 \% \text { and vapour } 20 \%\end{array}$ & 7.35 & 6.34 & 9.05 & 22.74 & 1.17 & 73.30 & 2.79 & 4.43 \\
\hline $\begin{array}{l}\text { Forced draft saturated with } \\
\mathrm{O} 2-27 \% \text { and vapour } 15 \%\end{array}$ & 6.4 & 6.9 & 7.14 & 20.44 & 2.09 & 73.42 & 4.05 & 3.14 \\
\hline $\begin{array}{c}\text { Forced draft saturated with } \\
\text { (impulse mode) } \mathrm{O} 2-25 \% \text { and } \\
\text { vapour } 12 \%\end{array}$ & 3.13 & 5.86 & 5.16 & 14.15 & 5.62 & 75.32 & 4.91 & 2.72 \\
\hline $\begin{array}{c}\text { Vapour and air forced draft } \\
\text { (impulse mode) } \mathrm{O} 2-21 \% \text {, and } \\
\text { vapour } 10 \%\end{array}$ & 1.09 & 5.21 & 2.94 & 9.24 & 9.73 & 76.74 & 4.29 & 1.24 \\
\hline
\end{tabular}

Rather often underground gasification is aimed at methane generation as the gas is the basic combustible gas currently used by public utilities and chemical industry. However, its generation as power raw material is rather complicated process and WUCG efficiency cannot be always confirmed by economic expediency.

Independently, the authors studied the activation process using various catalyzers but that concerned nothing else but coal gasification. It is common knowledge that increase of methane share in basic mixture is performed by means of applying catalyzers in the form of metals of 8th group of Mendeleev periodic system. Above all, it concerns iron and nickel owing to its availability and low cost. Corporate authors [1,3,] substantiated the process theoretically focusing on the proposed innovative technological WUCG scheme represented in Fig. 1. 


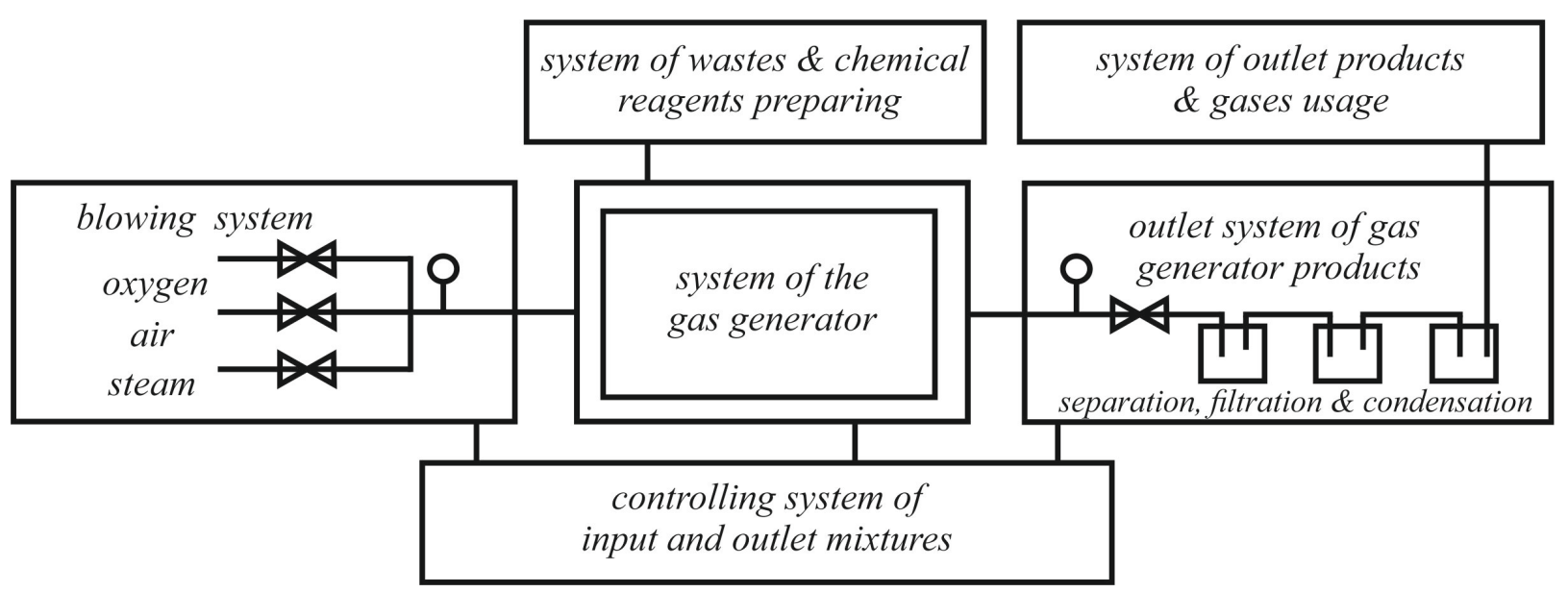

Fig. 1 Principle technological scheme of coal gasification with utilization of mining and other wastes

The presented technologic scheme can be implemented as for underground coal gas generator, also as for the gasgene on the surface. For the surface gasifier it is necessary to ensure the gasification process compliance within combustion and conversion zones. So, we have to provide the activation, inhibiting of the process proper thermal insulation of the system in accordance with the technical and technological implementation of the gas generator.

The research confirms that application of water-vapour forced draft makes it possible to generate alternative to natural gas. However, maximum concentration of the gas in outgoing mixture was $15-$ $20 \%$. Naturally, the success is essential but the availability of other combustible gases plus variations with the reaction velocity involve their separation and independent use.

Determination of components of synthesis gas with further generation of chemical raw material and liquid fuel and lubrication sources is more important task. It is known that synthesized gas is determined by means of hydrogen-carbonic oxide ratio within outgoing mixture of underground gas generator. Catalyzers and activators supply to transition zone leads to the changes in the reaction velocity as well as the densification of required combustible gases within outgoing flow. Correction of a conversion zone helps orienting generator gas to the required combustible mixtures with minimum variations in composition, modes, and techniques of forced-draft mixture supply to fire face.

Use of extra well for the supply of the prepared waste, chemical catalyzers and reagents makes it possible to lengthen reaction channel up to 40 meters; however, availability of extra well adds value to strip mining and primary mining. Unfortunately, the process is too complicated to be simulated with the help of laboratory facilities or bench ones.

\section{Economic Evaluation of the Project}

For the economical evaluation and to assess the investment attractiveness was used analytical principles based on the methodology developed by the Committee of Industrial Development of United Nations organization (UNIDO - United Nations Industrial Development Organization). This methodology is very useful for effectiveness evaluation of high-budget investment projects. The mentioned in this article proposal of wastes utilization within the coal gasification by used of the technical equipment, the technological and financial support is just such project. So usage UNIDO methodology is proper for investigating the economic necessity and the time to return fixed assets and financial investment based on the reduced cost of generator gas and products of gasification. Therefore, the authors choose this methodology as the selection method of the present economic assessment of the creating underground or surface gasifier for mining and related industries wastes recycling.

According to the primary dates the methodology allows to carry out the forecast of cash flows and evaluate the project effectiveness using quantitative indicators. It can be done a preliminary feasibility and financial initiatives study to establish the risks of their industrial implementation [3,12,]. 
The input data of the project are: depth of gasification, parameters of opening and preparatory wells; geological, lithological and hydrological conditions of the strata; geological infringements and zones of high stresses; quality and geometrical characteristics of coal seam; management of rockmass pressure; ecological influence on the environment; presence customers of outlet products and other.

The output data of investigation are: discount pay-back period (DPB); net present value (NPV); internal rate of return (IRR) and profitability index (PI). These parameters give an opportunity to comprehensively assess the feasibility and feasibility of implementing high-budget projects.

Taking into account the advantages and disadvantages of the given indicators, to determine the investment attractiveness of the proposed technical and technological solutions of utilization the mining and related wastes is enough to installed three parameters of project evaluation (discount payback period, DPB; net present value, NPV and profitability index, PI). It should be noted that the calculation of investment attractiveness of investment initiatives is carried out according to planned indicators and their comparison with actual ones.

Detailed information about researches carried out on the assessment of the investment attractiveness of the projects for the three types of implementation of the gas generators (underground gas generator without wastes utilization; underground gas generator with wastes utilization; surface gas generator with wastes utilization) has been accurately described in $[1,3,13]$. Therefore, the authors will use the analysis of the final parameters for assessing the investment attractiveness of the project according to the planned and actual parameters (table 2).

Table 2 Indicators for assessing the investment attractiveness of the project (planned and actual)

\begin{tabular}{|c|c|c|c|c|c|c|}
\hline \multirow{2}{*}{ Parameters } & \multicolumn{2}{|c|}{$\begin{array}{c}\text { Underground gas generator } \\
\text { without wastes utilization }\end{array}$} & \multicolumn{2}{|c|}{$\begin{array}{c}\text { Underground gas generator with } \\
\text { wastes utilization }\end{array}$} & \multicolumn{2}{|c|}{$\begin{array}{c}\text { Surface gas generator with } \\
\text { wastes utilization }\end{array}$} \\
\cline { 2 - 7 } & $\begin{array}{c}\text { Planed } \\
\text { indicators }\end{array}$ & $\begin{array}{c}\text { Actual } \\
\text { indicators }\end{array}$ & $\begin{array}{c}\text { Planed } \\
\text { indicators }\end{array}$ & Actual indicators & $\begin{array}{c}\text { Planed } \\
\text { indicators }\end{array}$ & $\begin{array}{c}\text { Actual } \\
\text { indicators }\end{array}$ \\
\hline $\begin{array}{c}\text { Total discounted } \\
\text { profit, mln UAN }\end{array}$ & 173,10 & 137,16 & 185,48 & 5,18 & 23,01 & 27,34 \\
\hline $\begin{array}{c}\text { Capital investments, } \\
\text { mln UAN }\end{array}$ & 36,90 & 36,90 & 22,86 & 27,30 & 16,80 & 16,13 \\
\hline $\begin{array}{c}\text { Payback period of the } \\
\text { project, year }\end{array}$ & 0,8 & 0,9 & 1,2 & 1,9 & 1,1 & 1,3 \\
\hline $\begin{array}{c}\text { Project profitability } \\
\text { index }\end{array}$ & 4,70 & 3,73 & 8,10 & 0,18 & 1,35 & 1,56 \\
\hline
\end{tabular}

The analyze of results for the underground gas generator without wastes utilization. Actual profitability index was in 1,2 time less than planned. At the same time, the NPV is positive and the actual values are positive and the investment decision should be positive in both cases. The variation of the profitability index is similar to the change of the NPV, since in calculating this criterion, the value of the total NPV relative to the initial capital investment is taken into account. The actual rate of return was lower than planned. The payback period of the project is the similar as the planned and actual values, but in this case there is a main drawback of this method, namely, the fact that the project's profitability beyond the payback period is left out of consideration.

The analyze of results for the underground gas generator with wastes utilization. The resulting difference in indicators is significant and indicates a large scale deviation from the planned steps of the project. Taking into account the economic appraisal data of this investment project, it can be concluded that the proposed technical and technological solutions are positive both in terms of plans and in real terms. In fact, the period of project implementation in this case became a decisive factor in obtaining a final profit.

The analyze of results for surface gas generator with wastes utilization. Taking into account the economic appraisal data of this investment project, it can be concluded that the proposed technical and technological solutions regarding wastes utilization are the most investment attractive from the proposed investment projects. But the greatest advantage of investments invested in surface gas generator, it turned out that the implementation period was even shorter than planned and brought investors profits $20 \%$ more than was planned. 


\section{Conclusions}

The authors' practices concerning chemistry of reaction medium heating up and the results of initial temperature action within reaction channel of underground gas generator prove demonstratively the possibility to achieve flash point of industrial and municipal waste. In addition to coal-mining enterprises, gas generator may also be used to utilize both solid and liquid residuals of chemical industry, power industry, medicine etc.

The proposed technical and technological substantiation of waste utilization in georeactor systems basing upon WUCG with its focus on the reuse of useful components makes it possible to generate heat, extra power, and chemical substances from the waste energy, to reduce technogenic load on the environment, and to provide long-term operation period of underground gas generator.

Further, the generated combustion gases will be used to regulate gasification process to keep the temperatures within the operating limits. The temperatures are the most useful for efficient and economically expedient transformation of the mentioned waste into ash residuals. The gasification process is activated by means of oxygen densification within the incoming mixture of the gas generator and temperature decrease result from the increase of carbon dioxide content in it.

The results obtained by the authors show that processing of the mentioned waste allows generating associated secondary useful components. Proper catalysis should be used to generate the required end product. Formation of mixtures containing two combustible gases, i.e. hydrogen and carbonic oxide (synthesis gas), is the most expedient operation. It is also important to use methane in the process of decomposition into the mentioned gases. Mixture of the two gases is the basis for further generation of liquid fuels and lubricants. Moreover, it is required to form technical gas for its further use in chemical industry.

The proposed technological schemes concerning operation of gas generators and the determined material and thermal balance make it possible to implement commercial processing of multigenesis waste within the ecologically sound closed cycle. Economic estimation shows that depending upon the required volumes and quality of mining waste utilization pay-back period of the project will not be more than $0.8-1.9$ years.

\section{References}

[1] Dychkovskyi, R.O., Falshtynskyi, V.S., Cabana, E.C. (2017). The possibility of recycling mining waste in a closed cycle of underground gas generator. Materials of the international conference "Miners Forum - 2017", pp. 38-46.

[2] Tabachenko M.M., Samusia V.I., Dychkovskyi, R.O, Falshtynskyi, V.S. (2012). New principles of heat pump and cogeneration technologies for the exhaust heat usage. Dnipro.: National Mining University, available at: http://www.twirpx.com/file/2141251/

[3] Dychkovskyi, R.O, (2013). Scientific principles of synthesis of technologies for the extraction of coal in weakly metamorphosed rocks. Dnipro.: National Mining University, available at: http://scihub.nmu.org.ua/handle/NMUUA_2310-8339/132

[4] Falshtyns'kyy, V., Dychkovs'kyy, R., Lozyns'kyy, V., \& Saik, P. (2013). Justification of the gasification channel length in underground gas generator. Mining of Mineral Deposits, pp.125132, available at: http://dx.doi.org/10.1201/b16354-23

[5] Falshtynskyi, V.S., Dychkovskyi, R.O, Stańczyk, K, Świadrowski, Je, Lozynskyi, V.G. (2010). Justification of technological schemes of the experimental coal mine gas generator. Naukovyi Visnyk Natsionalnoho Hirnychoho Universytetu, (3), pp. 34-38, available at: http://ir.nmu.org.ua/bitstream/handle/123456789/146951/02.pdf?sequence=1

[6] Pivnyak, G.G., Tabachenko, M.M., Dychkovskyi, R.O. (2013). The influence of temperature conditions on the efficiency of recovery reactions during gasification of coal seams. Mining of Mineral Deposits, pp. 331-335, available at: http://rr.nmu.org.ua/pdf/2013/20131016-44.pdf 
[7] Falsztinskij, W.S., Dyczkowskij, R.O., Lozinskij W.G. (2010). Ekonomiczne uzasadnienie celowości doszczelniania skał stropowych nad obszarem podziemnego zgazowania węgla metodą otworów wiertniczych. Prace naukowe GIG: Górnictwo i Środowisko, Kwartalnik, pp.51-59, available at: https://www.infona.pl/resource/bwmeta1.element.baztech-articleBSL9-0046-0013/content/partDownload/9cb800de-51d1-3179-891e-4fe63214435f

[8] Falshtynskyy, V., Dychkovskyy, R., Lozynskyy, V., \& Saik, P. (2012). New method for justification the technological parameters of coal gasification in the test setting. School of Underground Mining 2012, pp. 201-208, available at: http://dx.doi.org/10.1201/b13157-35

[9] Falshtynskyi, V.S., Dychkovskyi, R.O, Svietkina, O.Ju. (2010). The possibility of gasification of technical and household wastes in underground gas generators. Materials of the international conference "Miners Forum-2010", pp.176-182, available at: https://scholar.google.com/scholar?cluster=3806808988043994884\&hl=en\&oi=scholarr

[10] Emanuel, N.M., Knorre, D.G., (1974). Course of chemical kinetics. Moscow: Vysshaja shkola.

[11] Lavrov, N.V. (1957). Physical and chemical bases of combustion and gasification of fuel. Moscow: Metallizdat, 40 p.)

[12] Bayura, D. (2002). The methodology of UNIDO. Ukrainian Investment Newspaper. 49, (321).

[13] Dychkovskyi, R., Avdiushchenko, A., Lozynskyi V. (2017) Some Economic Indicators of Coal Mining from Thin Seams. Trans Tech Publication Ltd: Advanced Engineering Forum: Sustainable Development of Industrial Regions, pp. 13-21, available at: https://www.scientific.net/AEF.22.13 